\title{
Article \\ Diversity of Essential Oils and the Respective Hydrolates Obtained from Three Pinus cembra Populations in the Austrian Alps
}

\author{
Remigius Chizzola ${ }^{1, * \mathbb{D}}$, Felix Billiani ${ }^{2}$, Stefan Singer ${ }^{3}$ and Johannes Novak ${ }^{1}$ \\ 1 Institute of Animal Nutrition and Functional Plant Compounds, University of Veterinary Medicine Vienna, \\ Veterinaerplatz 1, 1210 Vienna, Austria; Johannes.Novak@vetmeduni.ac.at \\ 2 Währingerstrasse 204/8, 1180 Wien, Austria; felix.billiani@gmx.at \\ 3 Stefan Singer Prünst 12, 3163 Rohrbach an der Gölsen, Austria; office@pflanzner.at \\ * Correspondence: Remigius.Chizzola@vetmeduni.ac.at; Tel.: +43-1-250-773-104
}

Citation: Chizzola, R.; Billiani, F.; Singer, S.; Novak, J. Diversity of Essential Oils and the Respective Hydrolates Obtained from Three Pinus cembra Populations in the Austrian Alps. Appl. Sci. 2021, 11, 5686. https://doi.org/10.3390/ app11125686

Academic Editor: Monica Gallo

Received: 27 May 2021

Accepted: 17 June 2021

Published: 19 June 2021

Publisher's Note: MDPI stays neutral with regard to jurisdictional claims in published maps and institutional affiliations.

Copyright: () 2021 by the authors. Licensee MDPI, Basel, Switzerland. This article is an open access article distributed under the terms and conditions of the Creative Commons Attribution (CC BY) license (https:// creativecommons.org/licenses/by/ $4.0 /)$.

\begin{abstract}
Pinus cembra, stone pine, is an Alpine coniferous tree rich in aromatic compounds. Twigs with needles are used commonly to produce essential oils for various purposes in pharmacy, food industry, and cosmetics. Hydrolates as byproducts of hydrodistillation encounter increasing interest owing to their aromatic properties. The variabilities in the compositions of essential oil and the related hydrolates are studied in samples from individual trees growing on three sites in the Austrian high mountain range. The essential oils have been obtained by steam distillation. All essential oils contained monoterpene hydrocarbons as main compounds, especially $\alpha$-pinene (36-37\%), $\beta$-phellandrene (27-30\%), and $\beta$-pinene (7-9\%). In contrast, the volatiles in the corresponding hydrolates were dominated by oxidized compounds as $\alpha$-terpineol (28-34\%), terpinen-4-ol (6-8\%), and verbenone $(6-7 \%)$. The pinene rich essential oils might be used in pharmacy as pinene containing oils from other Pinus species, while the hydrolates are of interest for cosmetics and other well-being promoting products.
\end{abstract}

Keywords: hydrolate; essential oil; Pinus cembra L.; $\alpha$-pinene; $\alpha$-terpineol; monoterpenes

\section{Introduction}

Pinus cembra L., Pinaceae, Swiss stone pine, or arrola pine, is an alpine evergreen coniferous tree distributed in Europe in the Alps and the Carpathian Mountains. It grows in pure or mixed stands at high altitudes, $1500-2200 \mathrm{~m}$, where it is well adapted to the alpine climate. Growing slowly, it can reach a height up to $25 \mathrm{~m}$ and an age of 1000 years [1]. However, due to natural competition and human activities such as alpine farming and timber extraction, the distribution of P. cembra has been seriously compromised, which has led to a displacement to marginal habitats [2-4].

Regionally, P. cembra has obtained economic significance. Commonly, the wood is used as building timber, for furniture production, and for artwork. Additionally, P. cembra is grown in parks and gardens as an ornamental tree.

Similar to other Pinus species, P. cembra is rich in aromatic volatile compounds and resins. These compounds are of interest for non-timber uses of the tree, and in some regions efforts are undertaken to promote this sector [5]. Essential oils represent the plant volatile fraction obtained by hydrodistillation or steam distillation; in the case of stone pine they are usually obtained from whole twigs with needles. In steam distillation, which is the widely used technique, a hot steam passing through the plant material extracts the volatile plant compounds. After condensation, the essential oils can be separated from the water phase [6]. Therefore, hydrolates or hydrosols are byproducts of the distillation, and contain low amounts of aromatic compounds soluble in water. Another increasingly applied technique uses supercritical $\mathrm{CO}_{2}$ as an extractant to isolate the volatile fraction from plants. By adding modifiers, the selectivity of the extraction can be regulated [7]. 
However, these techniques are more sophisticated and need more intricate equipment than the classical distillation process, and are therefore costly.

P. cembra essential oils have various applications in medicine and aromatherapy, in local liquor production, and in the fragrance industry. Similarly, due to their aromatic properties, hydrolates are of interest for cosmetics. Stone pine products are sold to promote well-being. The aromatic compounds of the wood are said to have positive effects on indoor climate although this claim is not supported by scientific evidence.

Several authors reported on the P. cembra essential oil composition. $\alpha$-Pinene, limonene, $\beta$-phellandrene, and $\beta$-pinene in varying proportions were the main compounds [8-11]. The plant material investigated for these reports came mainly from Eastern Europe or from botanical gardens. Volatiles emitted by P. cembra cones of different geographic origins in the French Alps include $\alpha$-pinene (67-70\%), $\beta$-pinene (18-20\%), and limonene $/ \beta$-phellandrene $(8-11 \%)$ [12]. Only a recent study dealt with plants from a location in the Austrian Alps [13]. This study reports, in twig tips with needles, $44-48 \% \alpha$-pinene, $13-17 \% \beta$-phellandrene, $7-9 \% \beta$-pinene, $4-6 \%$ limonene, and $5-7 \%$ germacrene $\mathrm{D}$. As the evergreen tree produces large amounts of branches and greenery, this plant's raw material appears to be suitable for biosourcing interesting fractions or molecules. Products from other Pinus species are of medical interest or, as in the case of turpentine oils, have industrial applications [14]. As the biological activities may change with the composition of the essential oil, a more detailed knowledge of the oil composition becomes necessary.

As the variability of the volatiles in this species is not yet well documented and there are no reports on volatiles in P. cembra hydrolates, the focus of the present research was:

(1) To investigate the variability in essential oil composition from three different collection sites;

(2) To take sample from individual trees to get an insight in the chemical variation within populations;

(3) To obtain data on the volatiles in the hydrolates and to learn more about the correlation to their corresponding essential oils.

To obtain the essential oils and hydrolates, we used a simple steam distillation unit which can be easily installed on the collecting sites of the plants.

\section{Materials and Methods}

\subsection{Plant Material}

The plant material was collected during September 2015 on three sites in the Austrian Alps: Kemetgebirge, Stoderalm (KEM, Styria, 47 $27^{\prime} 56^{\prime \prime} \mathrm{N}, 13^{\circ} 49^{\prime} 37^{\prime \prime} \mathrm{E}$ and $47^{\circ} 28^{\prime} 02^{\prime \prime} \mathrm{N}$, $13^{\circ} 49^{\prime} 15^{\prime \prime}$ E, 1660-1701 m); Defereggental, Oberhauser Alm (DEF, East Tyrol, 46 $56^{\prime} 40^{\prime \prime}$ N, $12^{\circ} 13^{\prime} 12^{\prime \prime}$ E, 1660-1701 m); and Sirnitz, Hochrindl (SIR, 46 $51^{\prime} 57^{\prime \prime} \mathrm{N}, 1^{\circ} 59^{\prime} 09^{\prime \prime} \mathrm{E}$, 1498-1588 m). The Kemetgebirge site is located north of the central Alpine ridge, while the Sirnitz and Defereggental sites are located on the south side of the Alpine chain. On each site, 10 individual trees growing within a radius of 75-225 m were samples. The diameters of the trees' trunk ranged from 68 to $250 \mathrm{~cm}$. Approximately $20 \mathrm{~kg}$ of apparently healthy branches, with a diameter of up to $1.5 \mathrm{~cm}$, including the shoot tips and the needles, were taken from each tree within a height range of 1.5 to $10 \mathrm{~m}$. Voucher specimens from each site were deposited in the Herbarium of the University of Vienna (WU, https: / / www.jacq.org/\#database, accessed on 18 June 2021) with the numbers WU0122822, WU0122823, and WU0122824 for SIR, KEM, and DEF, respectively. From each tree, a portion of one hundred grams of the shredded material was transported in an airtight plastic bag to the laboratory, where dry matter was determined at $125^{\circ} \mathrm{C}$ for $1.5 \mathrm{~h}$ in a drying chamber.

\subsection{Steam Distillation}

The essential oils and hydrolates were obtained in a medium scale copper alembic type steam distillation unit, consisting of an 80 liter boiler fired with wood filled with $30 \mathrm{~L}$ water to produce the steam. About $12+/-0.2 \mathrm{~kg}$ freshly chopped branches with 
needles were set atop the boiler in a $40 \mathrm{~L}$ column. A condenser connected to the column was constantly supplied with $5^{\circ} \mathrm{C}$ cold water so the condensed essential oil and hydrolate could be caught and separated in a $1000 \mathrm{~mL}$ separating funnels. While the hydrolate was drained into a $10 \mathrm{~L}$ canister, the essential oil remained in the funnel and was collected and its amount measured at the end of the distillation process. The distillation was stopped after approximately $1 \mathrm{~h}+/-15 \mathrm{~min}$ when $7.7 \mathrm{~L}$ hydrolate were drained.

Prior to GC/MS the essential oils were diluted 1:100 with hexane. The hydrolates $(100 \mathrm{~mL})$ were extracted with $10 \mathrm{~mL}$ hexane in a separatory funnel. The hexane layer was separated from the water, dried over sodium sulfate, and kept at $-18{ }^{\circ} \mathrm{C}$ until further GC/MS analysis.

\section{3. $G C / M S$}

The GC/MS system consisted of 6890 (Agilent Technologies, Santa Clara, CA, USA) equipped with a 59772 MSD Mass selective detector and a $30 \mathrm{~m} \times 25 \mathrm{~mm}$ fused silica column coated with $0.25 \mu \mathrm{m}$ HP-5MS-column. The injector temperature was set at $250{ }^{\circ} \mathrm{C}$ and the injection volume was $1 \mu \mathrm{L}$ under a split relation of 1:10. Helium was the carrier gas at a velocity of $1.4 \mathrm{~mL} / \mathrm{min}$ in the constant flow mode. The oven temperature raised from $60{ }^{\circ} \mathrm{C}$ to $320^{\circ} \mathrm{C}$ at a rate of $6^{\circ} \mathrm{C} / \mathrm{min}$. The MSD recorded the mass fragments in the range $m / z 40$ to 500. The spectral libraries Wiley 275 and NIST 08 were used to identify the mass spectra. Additionally, retention indices were calculated using a mix of C8-C30 n-alkanes analyzed under the same conditions $[15,16]$. The peak areas from the total ion current without any correction were taken to calculate the percent composition of the essential oils and hydrolates.

\subsection{Statistical Analysis}

The statistical analyses were completed with the package SPSS for Windows, version 26.0 (IBM Corporation, Armonk, NY, USA). A one-way analysis of variance (ANOVA) with Tukey post hoc test evaluated the differences between the population for the individual essential oil compounds. For essential oils and hydrolate volatiles, the relation between major essential oil compounds was studied by a principal component analysis (PCA) using the samples as cases and the essential oil compounds as variables. Data was Z-transformed before calculating the loadings of the variables and scores of the samples.

\section{Results and Discussion}

\subsection{Essential Oil Yield}

Branches with needles were harvested from ten trees on each of the investigated sites. The essential oil yield calculated on a dry matter basis was lowest on the site KEM (1.29\% $v / w)$ and comparable for the sites DEF and SIR (1.60\% and $1.66 \% v / w$, respectively). The content of volatiles varies widely within the P. cembra tree. While unripe cones are rich in essential oils $(2.4-3.0 \%)$ the wood is very low in these compounds [10,13]. For needles and branches, essential oil contents range from 0.46 to $0.66 \%$ in plants growing in Poland [10], to 1.1 to $2.5 \%$ from Austrian plants [13], and 2.45\% in trees from Romania [8].

\subsection{Essential Oil Composition}

The composition of the essential oils is presented in Table 1. Monoterpene hydrocarbons were predominant, accounting for $76-80 \%$ of the essential oil, with $\alpha$-pinene (approximately 37\%) and $\beta$-phellandrene (27.5-30.0\%) as the two main compounds in all samples. $\alpha$-Pinene is widely occurring in essential oils. Pinus essential oils with $\alpha$ pinene as a major compound are pharmaceutically used in inhalation products, unctions, or as bath additives [17]. Essential oils from Pinus peuce, having comparable pinene and $\beta$-phellandrene contents to the present P. cembra essential oil, showed promising anticancer and anti-inflammatory activities [18]. The analytical column used did not separate limonene from $\beta$-phellandrene. Previous experiences report that P. cembra essential oil contains more $\beta$-phellandrene than limonene $[9,13]$. $\beta$-Pinene $(7.0-9.0 \%)$ was a further 
remarkable monoterpene hydrocarbon, while the percentages of camphene and myrcene remained below $2-3 \%$. Oxidized monoterpenes represented, on average, $1.9-2.6 \%$ of the essential oil, with the main compounds of thymol methylether $(0.5-0.8 \%)$, bornyl acetate $(0.4-0.7 \%)$, and cryptone $(0.3-0.5 \%)$. Other compounds of this class mostly had percentages of $0.1 \%$ or less. Amongst the sesquiterpene hydrocarbons, germacrene $\mathrm{D}$ and $\delta$-cadinene came to $4.3-7.4 \%$ and $2.1-2.8 \%$ of the essential oil, respectively. Other compounds from this class were below $1 \%$ each. Finally, six oxidized sesquiterpenes could be identified; they occur at low levels, together representing less than $1.4 \%$ of the oil, each usually below $0.4 \%$. Diterpenoids were not present in the actual essential oils, in contrast to essential oils obtained in a laboratory scale Clevenger type hydrodistillation device, which after three hours contained small amounts of diterpenes [11,13].

Table 1. Composition of the essential oil (\%) from Pinus cembra.

\begin{tabular}{|c|c|c|c|c|c|c|c|c|c|c|}
\hline \multirow[b]{2}{*}{ RI } & \multirow[b]{2}{*}{ Compound } & \multicolumn{3}{|c|}{ KEM } & \multicolumn{3}{|c|}{ DEF } & \multicolumn{3}{|c|}{ SIR } \\
\hline & & Mean & SD & Max & Mean & SD & Max & Mean & SD & Max \\
\hline & Oil yield $(\% v / w)$ & 1.29 & 0.27 & & 1.6 & 0.24 & & 1.66 & 0.42 & \\
\hline \multicolumn{11}{|c|}{ Monoterpene Hydrocarbons } \\
\hline 922 & Tricyclene & 0.1 & $<0.05$ & 0.2 & 0.2 & $<0.05$ & 0.2 & 0.2 & 0.1 & 0.2 \\
\hline 931 & $\alpha$-Thujene & $<0.05$ & $<0.05$ & $<0.05$ & $<0.05$ & $<0.05$ & 0.1 & $<0.05$ & $<0.05$ & 0.1 \\
\hline 938 & $\alpha$-Pinene & 36.8 & 6.2 & 44.8 & 37.2 & 2.6 & 42.2 & 36.8 & 5.0 & 43.9 \\
\hline 950 & Camphene & 1.6 & 0.8 & 3.1 & 1.7 & 0.8 & 3.5 & 1.8 & 0.9 & 3.1 \\
\hline 978 & $\beta$-Pinene & 7.0 & 2.4 & 10.3 & 8.7 & 1.6 & 10.6 & 9.0 & 2.0 & 11.9 \\
\hline 993 & Myrcene * & $1.2 \mathrm{a}$ & 0.2 & 1.6 & $1.4 \mathrm{ab}$ & 0.1 & 1.6 & $1.4 \mathrm{~b}$ & 0.2 & 1.6 \\
\hline 1003 & $\alpha$-Phellandrene & 0.1 & $<0.05$ & 0.2 & 0.1 & $<0.05$ & 0.2 & 0.2 & 0.1 & 0.2 \\
\hline 1009 & 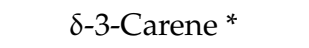 & $1.2 \mathrm{ab}$ & 0.6 & 2.7 & $0.5 \mathrm{a}$ & 0.5 & 1.6 & $1.2 \mathrm{~b}$ & 0.4 & 1.8 \\
\hline 1018 & $\alpha$-Terpinene & $<0.05$ & $<0.05$ & 0.1 & $<0.05$ & $<0.05$ & $<0.05$ & $<0.05$ & $<0.05$ & 0.1 \\
\hline 1027 & p-Cymene & 0.1 & 0.05 & 0.2 & 0.1 & 0.05 & 0.1 & 0.1 & 0.1 & 0.2 \\
\hline 1032 & $\beta$-Phellandrene ** & 27.5 & 5.4 & 37.8 & 29.8 & 3.0 & 33.5 & 30.0 & 4.8 & 37.2 \\
\hline 1062 & $\gamma$-Terpinene & 0.1 & $<0.05$ & 0.1 & 0.1 & $<0.05$ & 0.1 & 0.1 & $<0.05$ & 0.1 \\
\hline 1089 & Terpinolene & 0.5 & 0.3 & 1.2 & 0.4 & 0.2 & 0.9 & 0.6 & 0.3 & 1.0 \\
\hline & Sum & 76.3 & & & 80.3 & & & 81.3 & & \\
\hline \multicolumn{11}{|c|}{ Oxidised Monoterpenes } \\
\hline 1097 & $\alpha$-Pinene-epoxide & 0.1 & $<0.05$ & 0.1 & 0.1 & $<0.05$ & 0.1 & $<0.05$ & $<0.05$ & 0.1 \\
\hline 1123 & trans-Pinene-hydrate & & & & $<0.05$ & $<0.05$ & 0.1 & $<0.05$ & $<0.05$ & 0.1 \\
\hline 1129 & $\alpha$-Campholenal & & & & $<0.05$ & $<0.05$ & $<0.05$ & $<0.05$ & $<0.05$ & 0.1 \\
\hline 1141 & trans-Pinocarveol & $<0.0$ & 0.1 & 0.1 & 0.1 & $<0.05$ & 0.1 & 0.1 & 0.1 & 0.2 \\
\hline 1147 & Camphor & & & & $<0.05$ & $<0.05$ & $<0.05$ & $<0.05$ & $<0.05$ & 0.1 \\
\hline 1148 & trans-Verbenol & $<0.05$ & $<0.05$ & 0.1 & 0.1 & $<0.05$ & 0.1 & $<0.05$ & 0.1 & 0.2 \\
\hline 1165 & Pinocarvone & 0.1 & $<0.05$ & 0.1 & 0.1 & $<0.05$ & 0.1 & $<0.05$ & $<0.05$ & 0.1 \\
\hline 1168 & Borneol & $<0.05$ & $<0.05$ & 0.1 & $<0.05$ & $<0.05$ & 0.1 & 0.1 & 0.1 & 0.2 \\
\hline 1176 & Isopinocamphone & & & & $<0.05$ & $<0.05$ & $<0.05$ & $<0.05$ & $<0.05$ & $<0.05$ \\
\hline 1180 & Terpinen-4-ol & $<0.05$ & $<0.05$ & 0.1 & 0.1 & $<0.05$ & 0.1 & 0.1 & $<0.05$ & 0.1 \\
\hline 1188 & Cryptone & 0.4 & 0.4 & 1.1 & 0.5 & 0.2 & 0.9 & 0.3 & 0.5 & 1.7 \\
\hline 1192 & $\alpha$-Terpineol & 0.2 & 0.1 & 0.3 & 0.2 & 0.1 & 0.3 & 0.2 & 0.1 & 0.3 \\
\hline 1197 & Myrtenal & 0.1 & $<0.05$ & 0.1 & 0.1 & $<0.05$ & 0.1 & 0.1 & 0.1 & 0.2 \\
\hline 1211 & Verbenone & $<0.05$ & $<0.05$ & 0.1 & 0.1 & $<0.05$ & 0.1 & $<0.05$ & 0.1 & 0.2 \\
\hline 1238 & Thymol-methylether & 0.5 & 0.2 & 0.9 & 0.6 & 0.2 & 0.8 & 0.8 & 0.3 & 1.2 \\
\hline 1244 & Cuminic aldehyde & 0.1 & 0.1 & 0.2 & 0.1 & $<0.05$ & 0.2 & $<0.05$ & 0.1 & 0.3 \\
\hline \multirow[t]{2}{*}{1288} & Bornyl acetate & 0.5 & 0.3 & 1.2 & 0.6 & 0.4 & 1.6 & 0.7 & 0.5 & 1.6 \\
\hline & Sum & 1.9 & & & 2.6 & & & 2.6 & & \\
\hline
\end{tabular}


Table 1. Cont.

\begin{tabular}{|c|c|c|c|c|c|c|c|c|c|c|}
\hline \multirow[b]{2}{*}{ RI } & \multirow[b]{2}{*}{ Compound } & \multicolumn{3}{|c|}{ KEM } & \multicolumn{3}{|c|}{ DEF } & \multicolumn{3}{|c|}{ SIR } \\
\hline & & Mean & SD & Max & Mean & SD & Max & Mean & SD & $\operatorname{Max}$ \\
\hline \multicolumn{11}{|c|}{ Sesquiterpene Hydrocarbons } \\
\hline 1354 & $\alpha$-Cubebene & 0.2 & 0.2 & 0.5 & 0.1 & 0.1 & 0.5 & 0.1 & 0.1 & 0.3 \\
\hline 1380 & $\alpha$-Copaene & 0.2 & $<0.05$ & 0.2 & 0.1 & $<0.05$ & 0.2 & 0.1 & $<0.05$ & 0.2 \\
\hline 1391 & $\beta$-Bourbonene & $<0.05$ & $<0.05$ & $<0.05$ & $<0.05$ & $<0.05$ & 0.1 & $<0.05$ & $<0.05$ & 0.1 \\
\hline 1394 & $\beta$-Cubebene & 0.2 & 0.1 & 0.4 & $<0.05$ & 0.1 & 0.2 & 0.1 & 0.1 & 0.2 \\
\hline 1425 & $\beta$-Caryophyllene & 0.9 & 0.5 & 2.3 & 1.0 & 0.4 & 1.5 & 1.0 & 0.4 & 1.6 \\
\hline 1446 & Aromadendrene & 0.2 & 0.1 & 0.4 & 0.2 & 0.1 & 0.4 & 0.2 & 0.1 & 0.4 \\
\hline 1460 & $\alpha$-Humulene & 0.7 & 0.5 & 1.2 & 0.8 & 0.4 & 1.5 & 0.9 & 0.5 & 1.7 \\
\hline 1470 & $\begin{array}{c}\text { epi-Bicyclo- } \\
\text { sesquiphellandrene }\end{array}$ & 0.1 & $<0.05$ & 0.2 & 0.1 & $<0.05$ & 0.1 & 0.1 & $<0.05$ & 0.2 \\
\hline 1483 & $\gamma$-Muurolene * & $0.9 \mathrm{~b}$ & 0.3 & 1.4 & $0.3 \mathrm{a}$ & 0.4 & 1.1 & $0.5 \mathrm{ab}$ & 0.2 & 0.8 \\
\hline 1488 & Germacrene D* & $7.4 \mathrm{~b}$ & 2.2 & 10.4 & $4.5 \mathrm{a}$ & 2.7 & 9.9 & $4.3 \mathrm{a}$ & 2.3 & 7.4 \\
\hline 1502 & Bicyclogermacrene & 1.8 & 0.6 & 2.7 & 1.5 & 0.3 & 2.1 & 1.3 & 0.4 & 1.8 \\
\hline 1505 & $\alpha$-Muurolene * & $0.7 \mathrm{~b}$ & 0.2 & 1.2 & $0.6 \mathrm{ab}$ & 0.1 & 0.6 & $0.5 \mathrm{a}$ & 0.1 & 0.7 \\
\hline 1513 & $\beta$-Bisabolene & 0.3 & 0.3 & 0.9 & 0.6 & 0.2 & 1.0 & 0.7 & 0.3 & 1.2 \\
\hline 1520 & $\gamma$-Cadinene $*$ & $1.4 \mathrm{a}$ & 0.3 & 1.7 & $1.2 \mathrm{ab}$ & 0.2 & 1.5 & $1.0 \mathrm{~b}$ & 0.3 & 1.4 \\
\hline 1530 & $\delta$-Cadinene & 2.8 & 0.5 & 3.7 & 2.2 & 0.3 & 2.7 & 2.1 & 0.6 & 2.8 \\
\hline 1539 & trans-Cadina-1,4-diene & 0.1 & $<0.05$ & 0.2 & 0.1 & $<0.05$ & 0.1 & 0.1 & $<0.05$ & 0.1 \\
\hline 1545 & $\alpha$-Cadinene & 0.2 & 0.1 & 0.3 & 0.2 & $<0.05$ & 0.2 & 0.1 & $<0.05$ & 0.2 \\
\hline \multirow[t]{2}{*}{1548} & cis- $\alpha$-Bisabolene & 0.1 & 0.1 & 0.2 & $<0.05$ & 0.1 & 0.2 & 0.1 & 0.1 & 0.3 \\
\hline & Sum & 18.3 & & & 13.6 & & & 13.4 & & \\
\hline \multicolumn{11}{|c|}{ Oxidised Sesquiterpenes } \\
\hline 1583 & Germacrene D-4-ol & 0.4 & 0.2 & 0.8 & 0.4 & 0.2 & 0.9 & 0.2 & 0.1 & 0.3 \\
\hline 1585 & Spathulenol & 0.1 & 0.1 & 0.3 & 0.1 & 0.1 & 0.2 & $<0.05$ & 0.1 & 0.2 \\
\hline 1591 & Caryophyllene oxide & 0.2 & 0.1 & 0.4 & 0.2 & 0.1 & 0.3 & 0.1 & 0.1 & 0.2 \\
\hline 1650 & $\tau$-Cadinol * & $0.4 \mathrm{~b}$ & 0.2 & 0.7 & $0.4 \mathrm{ab}$ & 0.1 & 0.6 & $0.2 \mathrm{a}$ & 0.1 & 0.3 \\
\hline 1663 & $\alpha-$-Cadinol & 0.3 & 0.1 & 0.6 & 0.2 & 0.1 & 0.3 & 0.2 & 0.1 & 0.3 \\
\hline \multirow[t]{3}{*}{1692} & $\alpha$-Bisabolol & 0.1 & 0.1 & 0.3 & 0.1 & $<0.05$ & 0.2 & 0.1 & 0.1 & 0.3 \\
\hline & Sum & 1.4 & & & 1.3 & & & 0.9 & & \\
\hline & Other & & & & & & & & & \\
\hline \multirow[t]{2}{*}{1199} & Estragol & 0.2 & 0.2 & 0.5 & 0.1 & 0.1 & 0.2 & 0.2 & 0.1 & 0.3 \\
\hline & Total Sum & 98.0 & & & 98.0 & & & 98.3 & & \\
\hline
\end{tabular}

* For these compounds means followed by the same letter are not significantly different according to a one-way ANOVA with Tukey post hoc test; ** also contains some limonene; SD: standard deviation $(n=10)$.

The main compounds, $\alpha$-pinene, $\beta$-phellandrene, $\beta$-pinene, and germacrene $D$ were found in all samples. This is in good agreement with the published literature, where these compounds were reported to occur in varying proportions. $\alpha$-Pinene ranged from $21.1 \%$ in trees from a Scotch arboretum [19] to $69.1 \%$ in samples from Romania [8]. To produce essential oils, branches with needles are usually the parts of the trees which are processed. Former research demonstrated that essential oil composition clearly differed between the needles and the twigs and branches. Needles had more $\alpha$-pinene and germacrene $D$ than the twig tips, but less limonene, $\beta$-phellandrene, and $\beta$-pinene $[10,13]$. Therefore, the composition of a commercially produced essential oil is strongly dependent on the ratio of twigs to needles in the distilled raw material.

A one-way analysis of variance testing the influence of sampling site on the individual essential oil compounds found significant differences between the sites only for germacrene $\mathrm{D}$, and the minor compounds myrcene, $\delta$-3-carene, $\gamma$-cadinene, $\alpha$-muurolene, $\gamma$-muurolene, and $\tau$-muurolol (Table 1). For germacrene $D$, the Tukey post hoc test indicated that this compound was higher in samples from KEM, in comparison to that of both other sites. Nevertheless, the main compounds, $\alpha$-pinene, $\beta$-phellandrene, and $\beta$-pinene had variation coefficient from 6.9 to $10 \%, 11$ to $16 \%$ and 17 to $32 \%$ in population DEF, SIR and KEM, respectively, suggesting that there is some variability within the populations. 
To get further insight into the variability, a principal component analysis was calculated with 30 essential oil compounds as variables and the samples as cases, and resulted in eight components with an Eigenvalue greater than one, accounting for $86.7 \%$ of the variability. The loadings of the compounds on the first two components, representing together $48.2 \%$ of the variability, are displayed in Figure $1 . \beta$-Phellandrene and $\beta$-pinene, as well as myrcene, had a high positive component 1 loading, while $\alpha$-pinene and germacrene D showed negative loadings on this component. All oxidized monoterpenes as minor essential oil constituents loaded positively on both components. The scores of the samples in Figure 2 show wide overlapping of the samples from the three sites, with most KEM samples scoring with a negative component 1 value. Samples from the DEF site having a lower within population variability were rather clustered in the center. Outliers S4, S8, and K7 in the lower right quadrant had the highest $\beta$-phellandrene percentages. Outlier S2 had relatively higher amounts of oxidized monoterpenes. Samples K3 and K4, with the lowest component 1 scorings, had relatively high amounts of the minor essential oil compounds $\delta$-cadinene, bicyclogermacrene, and $\gamma$-cadinene.

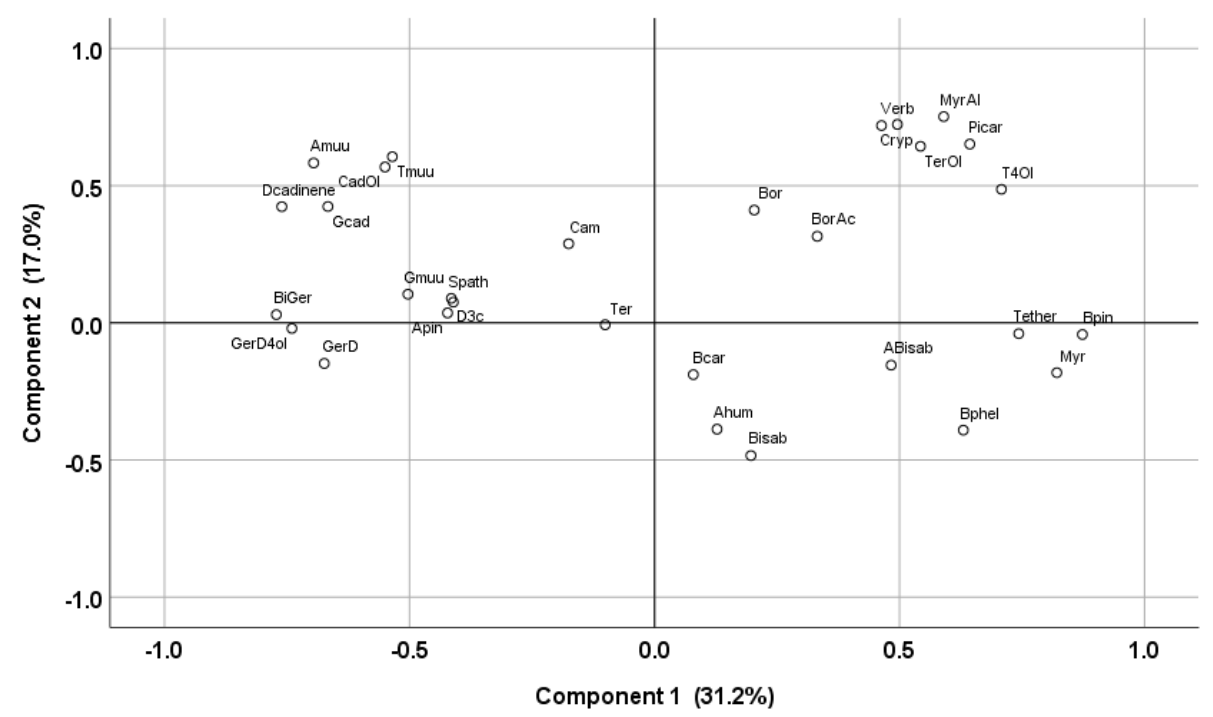

Figure 1. Essential oil compounds loading on the first two axes of a principal component analysis of P. cembra essential oils.

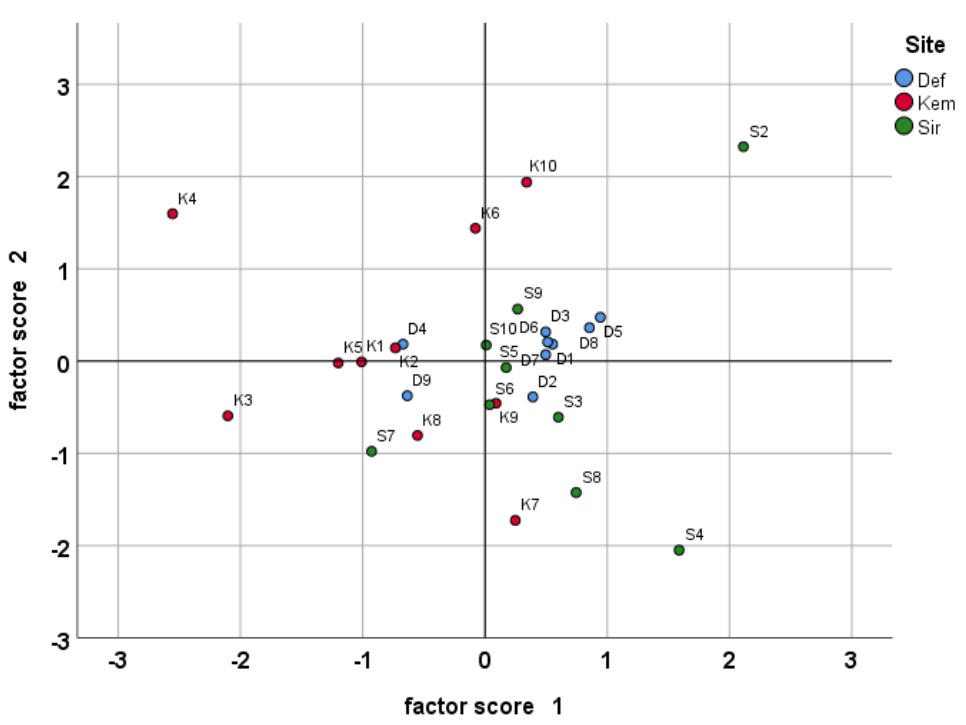

Figure 2. PCA scoring plot showing the essential oil samples from the individual P. cembra trees. 
ABisab: $\alpha$-bisabolol, Ahum: $\alpha$-humulene, Amuu: $\alpha$-muurolene, Apin: $\alpha$-pinene, Bcar: $\beta$-caryophyllene, BiGer: bicyclogermacrene, Bisab: $\beta$ bisabolene, Bor: borneol, BorAc: borny lacetate, Bphel: $\beta$-phellandrene, Bpin: $\beta$-pinene, CadOl: $\alpha$-cadinol, Cam: camphene, Cryp: cryptone, D3c: $\delta$-3-carene, Dcad: $\delta$-cadinene, Gcad: $\gamma$-cadinene, GerD: germacrene D, GerD4ol: germacrene D-4-ol, Gmuu: $\gamma$-muurolene, Myr: myrcene, MyrAl: myrtenal, Picar: trans-pinocarveol, Spath: spathulenol, T4Ol: terpinen-4-ol, Ter: terpinolene, TerOl: $\alpha$-terpineol, Tether: thymolmethylther, Tmuu: $\tau$-muurolol, and Verb: verbenone

A great variability of essential oils within a given population has also been reported in other conifers. In Pinus sylvestris, individuals rich in $\alpha$-pinene or $\delta$-3-carene occurred together within a stand [20]. High diversity of terpenes might be important to increase the resistance against herbivory [21].

\subsection{Composition of the Volatile Fractions from the Hydrolates}

The mean composition of the volatiles isolated from the hydrolates for the three sites is given in Table 2. Oxidized monoterpenes constituted the major fraction of hydrolate volatiles. Thirty compounds were identified, of which $\alpha$-terpineol was the dominant compound. This compound had, on average, $27.7-37.6 \%$ in the hydrolate volatiles, while in the distilled oil it reached only around $0.2 \%$. Applications of $\alpha$-terpineol, with its pleasant odor similar to lilac, are in various perfumes, cosmetics, soaps, and antiseptic products [22]. Terpinen-4-ol was the second major compound (6.3-7.8\%) from hydrolate volatiles, and this compound was very low in essential oil, at $0.1 \%$ or less. Further remarkable volatiles were verbenone (6.1-7.0\%), cis-p-Menth-2-en-1-ol (3.7-4.7\%), myrtenal (3.5-4.1\%), cryptone (3.2-4.0\%), and borneol (3.1-3.6\%). Oxidized sesquiterpenes reached $6.5-9.9 \%$ of the hydrolate volatiles, mainly with $\alpha$-cadinol (3.1-5.4\%) and $\tau$-muurolol (1.8-2.9\%). Terpene hydrocarbons were low in the hydrolate volatiles; on average $\alpha$-pinene $(1.0-2.2 \%), \beta$ phellandrene (0.9-1.9\%), germacrene D (1.3-5.6\%), and $\delta$-cadinene $(1.0-3.1 \%)$.

An ANOVA studying the influence of the population detected significant differences for $\alpha$-terpineol, $\alpha$-cadinol, $\tau$-muurolol, germacrene $D, \delta$-cadinene, $\alpha$-pinene, and $\beta$-phellandrene. The post hoc test showed that, in all cases, the samples from KEM differed from at least one of the other sites. It appears that KEM hydrolate volatiles had more terpene hydrocarbons and less oxidized monoterpenes than those from DEF and SIR.

A principal component analysis, with the hydrolate volatile compounds as variables and the samples as cases, has been calculated. Six components with an Eigenvalue greater than 1 were extracted from 23 variables. Figure 3 presents the loadings of the volatile compounds on the first two components. The main volatile constituent, $\alpha$-terpineol, as well as myrtenal, had a strong negative loading on component 1 ; further oxidized sesquiterpenes (terpinen-4-ol, piperitone, cis-p-menth-2-en-1-ol, and trans-p-menth-2-en-1-ol) showed a high component 2 loading, while others (cryptone, borneol, and camphor) had weak negative component 1 and component 2 loadings. The terpene hydrocarbons, in contrast, were all highly component 1 loading. The plotting of the first two components for the samples, as displayed in Figure 4, presents samples from SIR mainly with negative factor 1 scores, whiles those from KEM were mostly positively factor 1 scoring. Therefore, most KEM hydrolate samples appear to differ from those of both other sites. Samples D5, D9, and S7 had higher terpinen-4-ol, piperitone, and trans-p-menth-2-en-1-ol in their volatile fractions. Outlier $\mathrm{K} 5$ had the highest germacrene $\mathrm{D}$ and $\delta$-cadinene contents.

ABisab: $\alpha$-Bisabolol, Apin: $\alpha$-pinene, Bcar: $\beta$-caryophyllene, Bor: borneol, BorAc: bornylacetate, Bphel: $\beta$-phellandrene, CadOl: $\alpha$-cadinol, Camp: camphor, CMol; cis-pmenth-2-en-1-ol, Cryp: cryptone, Dcad: $\delta$-cadinene, Gcad: $\gamma$-cadinene, GerD: germacreneD, Lin: linalool, MeOl: mentha-1,5-dien-8-ol, MyrAl: myrtenal, Picar: trans-Pinocarveol, Piper: piperitone, Spath: spathulenol, T4Ol: terpinen-4-ol, Tcar: trans-carveol, TerOl: $\alpha-$ terpineol, Tether: thymolmethylether, TMol: trans-p-menth-2-en-1-ol, Tmuu: $\tau$-muurolol, and Verb: verbenone. 
Table 2. Composition of the hydrolate volatiles (\%) from Pinus cembra.

\begin{tabular}{|c|c|c|c|c|c|c|c|c|c|c|}
\hline \multirow[t]{2}{*}{ RI } & & \multicolumn{3}{|c|}{ KEM } & \multicolumn{3}{|c|}{ DEF } & \multicolumn{3}{|c|}{ SIR } \\
\hline & & Mean & SD & Max & Mean & SD & Max & Mean & SD & Max \\
\hline \multicolumn{11}{|c|}{ Monoterpene Hydrocarbons } \\
\hline 933 & $\alpha$-Pinene * & $2.2 \mathrm{~b}$ & 0.7 & 3.2 & $1.4 \mathrm{a}$ & 0.7 & 2.9 & $1.0 \mathrm{a}$ & 0.4 & 1.6 \\
\hline 978 & $\beta$-Pinene & 0.2 & 0.2 & 0.6 & & & & & & \\
\hline 1032 & $\beta$-Phellandrene $* * *$ & $1.9 \mathrm{~b}$ & 0.9 & 3.8 & $1.2 \mathrm{ab}$ & 0.5 & 2.2 & $0.9 \mathrm{a}$ & 0.5 & 1.9 \\
\hline & Sum & 4.4 & & & 2.6 & & & 1.9 & & \\
\hline \multicolumn{11}{|c|}{ Oxidized Monoterpenes } \\
\hline 1034 & 1,8-Cineol & 0.5 & 0.2 & 0.9 & 0.4 & 0.3 & 0.8 & 0.7 & 0.5 & 1.3 \\
\hline 1088 & Fenchone & 0.2 & 0.1 & 0.5 & 0.2 & 0.1 & 0.3 & 0.3 & 0.2 & 0.6 \\
\hline 1100 & Linalool & 0.6 & 1.1 & 3.7 & 0.2 & 0.4 & 1.3 & 0.2 & 0.4 & 1.2 \\
\hline 1112 & exo-Fenchol & 0.8 & 0.2 & 1.1 & 0.9 & 0.1 & 1.1 & 0.9 & 0.1 & 1.0 \\
\hline 1120 & cis-p-Menth-2-en-1-ol & 3.7 & 1.6 & 5.5 & 4.7 & 1.6 & 7.6 & 4.2 & 1.4 & 6.3 \\
\hline 1126 & $\alpha$-Campholenal & 0.3 & 0.1 & 0.6 & 0.3 & 0.2 & 0.6 & 0.3 & 0.2 & 0.5 \\
\hline 1137 & trans-Pinocarveol & 2.4 & 1.0 & 4.5 & 3.6 & 3.4 & 10.7 & 2.9 & 2.0 & 7.2 \\
\hline 1139 & tr.-p-Menth-2-en-1-ol & 0.7 & 0.4 & 1.4 & 1.5 & 1.2 & 3.3 & 1.4 & 0.7 & 2.2 \\
\hline 1143 & Camphor & 0.7 & 0.8 & 2.3 & 0.6 & 0.4 & 1.5 & 0.8 & 0.6 & 2.2 \\
\hline 1145 & trans-Verbenol & 1.0 & 0.5 & 1.6 & 0.9 & 0.2 & 1.3 & 0.9 & 0.4 & 1.4 \\
\hline 1147 & Camphene Hydrate & 0.6 & 0.4 & 1.3 & 0.6 & 0.4 & 1.3 & 0.4 & 0.2 & 0.8 \\
\hline 1160 & trans-Pinocamphone & 0.4 & 0.3 & 0.9 & 0.6 & 0.5 & 1.6 & 0.3 & 0.1 & 0.5 \\
\hline 1162 & Pinocarvone & 0.3 & 0.1 & 0.5 & 0.2 & 0.3 & 0.8 & 0.2 & 0.1 & 0.4 \\
\hline 1165 & Borneol & 3.1 & 1.6 & 6.1 & 3.5 & 1.1 & 5.5 & 3.6 & 1.5 & 6.8 \\
\hline 1167 & Mentha-1,5-dien-8-ol & 1.5 & 0.4 & 2.1 & 1.8 & 0.8 & 3.3 & 2.3 & 0.9 & 3.5 \\
\hline 1173 & cis-Pinocamphone & 0.6 & 0.2 & 0.9 & 0.6 & 0.3 & 1.1 & 0.6 & 0.2 & 1.1 \\
\hline 1177 & Terpinen-4-ol & 6.3 & 1.2 & 7.7 & 7.0 & 2.1 & 10.6 & 7.8 & 1.2 & 10.3 \\
\hline 1183 & p-Cymen-8-ol & 0.4 & 0.2 & 0.7 & & & & 0.4 & 0.3 & 1.2 \\
\hline 1186 & Cryptone & 4.0 & 1.8 & 6.1 & 3.2 & 1.6 & 5.0 & 3.0 & 1.7 & 5.1 \\
\hline 1190 & $\alpha$-Terpineol * & $27.7 \mathrm{a}$ & 5.4 & 34.6 & $33.1 \mathrm{ab}$ & 4.7 & 39.3 & $34.1 \mathrm{~b}$ & 4.1 & 40.5 \\
\hline 1196 & Myrtenal & 3.5 & 1.3 & 5.3 & 3.8 & 0.9 & 5.1 & 4.1 & 0.8 & 5.6 \\
\hline 1200 & trans-Piperol & 0.2 & 0.2 & 0.7 & 0.3 & 0.2 & 0.7 & 0.2 & 0.1 & 0.4 \\
\hline 1209 & Verbenone & 6.1 & 1.6 & 8.5 & 6.3 & 2.1 & 9.5 & 7.0 & 1.1 & 8.5 \\
\hline 1220 & trans-Carveol & 1.2 & 0.3 & 1.7 & 1.1 & 0.4 & 1.5 & 1.4 & 0.5 & 2.2 \\
\hline 1230 & $\begin{array}{c}\text { cis-p-Mentha-1(7),8-dien-2- } \\
\text { ol }\end{array}$ & 0.8 & 0.5 & 1.8 & 0.6 & 0.4 & 1.4 & 0.4 & 0.2 & 1.0 \\
\hline 1236 & Thymol-Methylether & 0.2 & 0.1 & 0.5 & 0.2 & 0.1 & 0.3 & 0.2 & 0.2 & 0.6 \\
\hline 1246 & Carvotanacetone & 0.5 & 0.2 & 0.7 & 0.4 & 0.3 & 0.9 & 0.5 & 0.3 & 0.8 \\
\hline 1256 & Piperitone & 1.7 & 0.9 & 3.6 & 3.7 & 2.6 & 8.2 & 2.7 & 1.4 & 5.9 \\
\hline 1261 & trans-Myrtanol & 0.3 & 0.3 & 0.9 & 0.2 & 0.1 & 0.4 & 0.3 & 0.3 & 0.9 \\
\hline \multirow[t]{2}{*}{1287} & Bornyl Acetate & 1.5 & 1.1 & 4.0 & 1.9 & 1.7 & 6.0 & 2.2 & 1.4 & 5.2 \\
\hline & Sum & 71.5 & & & 82.3 & & & 84.4 & & \\
\hline \multicolumn{11}{|c|}{ Sesquiterpene Hydrocarbons } \\
\hline 1423 & $\beta$-Caryophyllene & 0.3 & 0.5 & 1.3 & 0.2 & 0.2 & 0.5 & & & \\
\hline 1485 & Germacrene-D * & $5.6 \mathrm{~b}$ & 4.9 & 16.5 & $1.4 \mathrm{a}$ & 1.9 & 6.3 & $1.3 \mathrm{a}$ & 1.6 & 4.6 \\
\hline 1504 & $\alpha$-Muurolene & 0.3 & 0.2 & 0.6 & & & & & & \\
\hline 1519 & $\gamma$-Cadinene & 0.9 & 1.0 & 3.6 & 0.4 & 0.5 & 1.4 & 0.3 & 0.3 & 0.8 \\
\hline \multirow[t]{2}{*}{1527} & $\delta$-Cadinene & 3.1 & 2.7 & 10.3 & 1.5 & 1.2 & 3.9 & 1.0 & 1.0 & 2.9 \\
\hline & Sum & 10.2 & & & 3.4 & & & 2.5 & & \\
\hline \multicolumn{11}{|c|}{ Oxidized Sesquiterpenes } \\
\hline 1584 & Spathulenol & 0.4 & 0.2 & 0.7 & 0.3 & 0.2 & 0.5 & 0.2 & 0.2 & 0.6 \\
\hline 1634 & cis-Cadin-4-en-7-ol & 0.3 & 0.1 & 0.5 & 0.1 & 0.1 & 0.3 & 0.2 & 0.1 & 0.4 \\
\hline 1648 & $\tau$-Muurolol * & $2.9 \mathrm{~b}$ & 0.8 & 4.2 & $2.4 \mathrm{ab}$ & 0.9 & 4.2 & $1.8 \mathrm{a}$ & 0.8 & 2.9 \\
\hline 1652 & Torreyol & 0.6 & 0.3 & 1.3 & 0.5 & 0.2 & 1.0 & 0.5 & 0.2 & 0.9 \\
\hline 1661 & $\alpha$-Cadinol * & $5.4 \mathrm{~b}$ & 2.1 & 8.3 & $4.5 \mathrm{ab}$ & 1.7 & 8.2 & 3. a1 & 1.2 & 4.7 \\
\hline \multirow[t]{3}{*}{1690} & $\alpha$-Bisabolol & 0.3 & 0.5 & 1.4 & 0.6 & 0.3 & 1.3 & 0.8 & 0.6 & 1.7 \\
\hline & Sum & 9.9 & & & 8.5 & & & 6.5 & & \\
\hline & Total Sum & 96.0 & & & 96.8 & & & 95.4 & & \\
\hline
\end{tabular}

* For these compounds, means followed by the same letter are not significantly different according to a one-way ANOVA with Tukey post hoc test; ** also contains some limonene; SD: standard deviation $(n=10)$. 


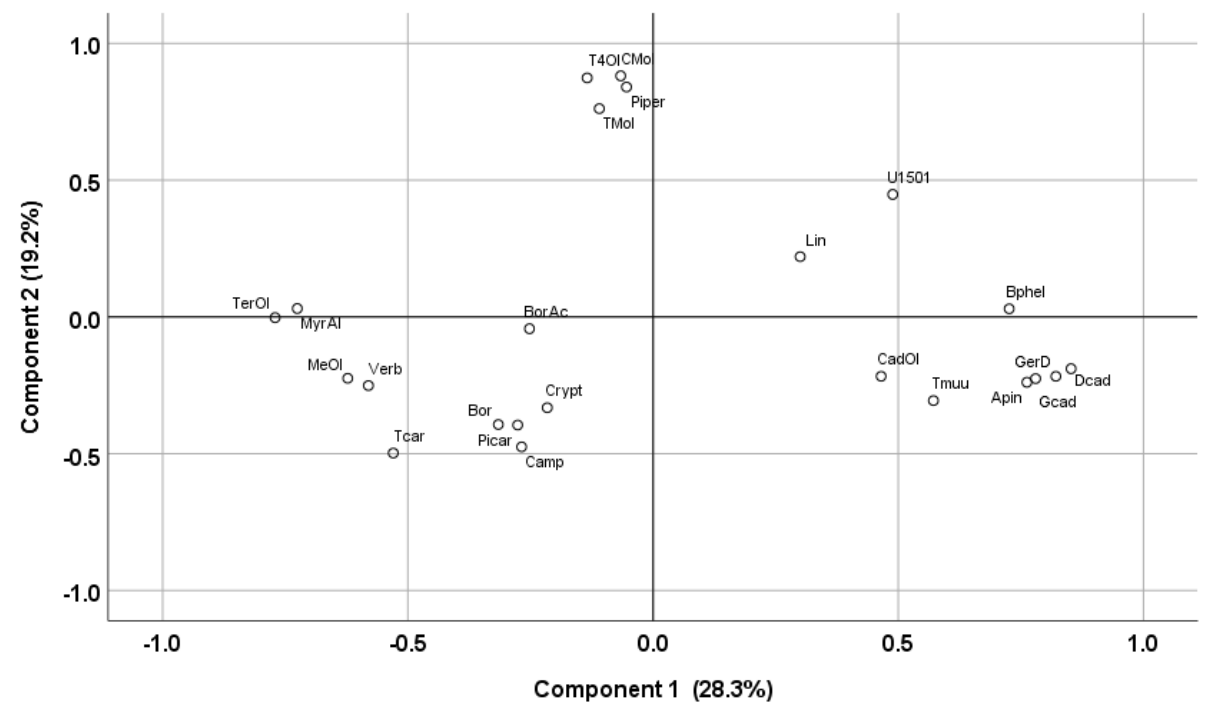

Figure 3. Hydrolate volatile compounds loading on the first two axes of a principal component analysis of $P$. cembra hydrolates.

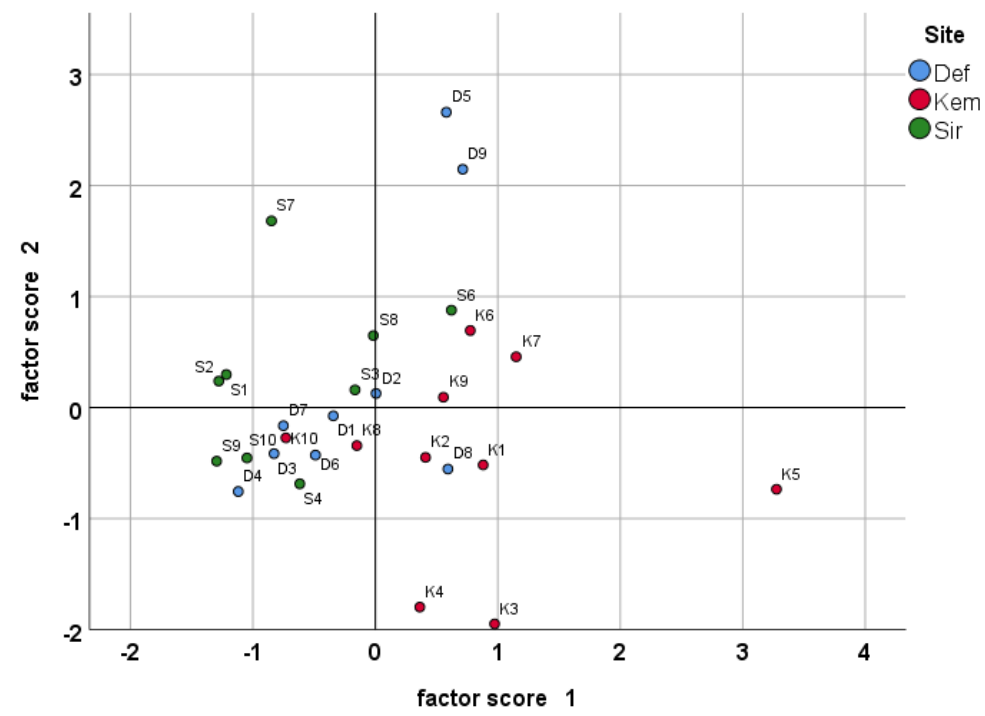

Figure 4. PCA scoring plot showing the hydrolate volatile samples from the individual P. cembra trees.

\subsection{Comparison of the Essential Oils with the Hydrolate Volatiles}

The comparison of Tables 1 and 2 shows that essential oils and the hydrolate volatiles differed significantly. Hydrocarbon terpenes as camphene, myrcene, $\delta$-3-carene, terpinolene, $\alpha$-humulene, and bicyclogermacrene could only be found in the distilled oils. $\beta$ Pinene was present in all essential oils, but could only be recovered in the hydrolate volatiles from KEM site. On the other hand, a range of oxidized monoterpenes occurred only in hydrolates; these were linalool, cis-p-menth-2-en-1-ol, trans-p-menth-2-en-1-ol, mentha-1,5-dien-8-ol, trans-carveol, and piperitone. Camphor, which could be detected in all hydrolate volatiles, was present only in a few essential oil samples at very low levels. The ratio of volatile percentages in hydrolate to distilled oil has been calculated for the compounds that occur in both sample types (Figure 5). Thus, terpene hydrocarbons having a ratio below one occurred mainly in the distilled oils, while oxidized compounds were more prominent in the respective hydrolate volatiles. In comparison to the essential oil, the hydrolate volatiles had a 158-, 186-, or 303-times higher percentage for the oxidized monoterpenes terpinen-4-ol, $\alpha$-terpineol, and verbenone, respectively. 


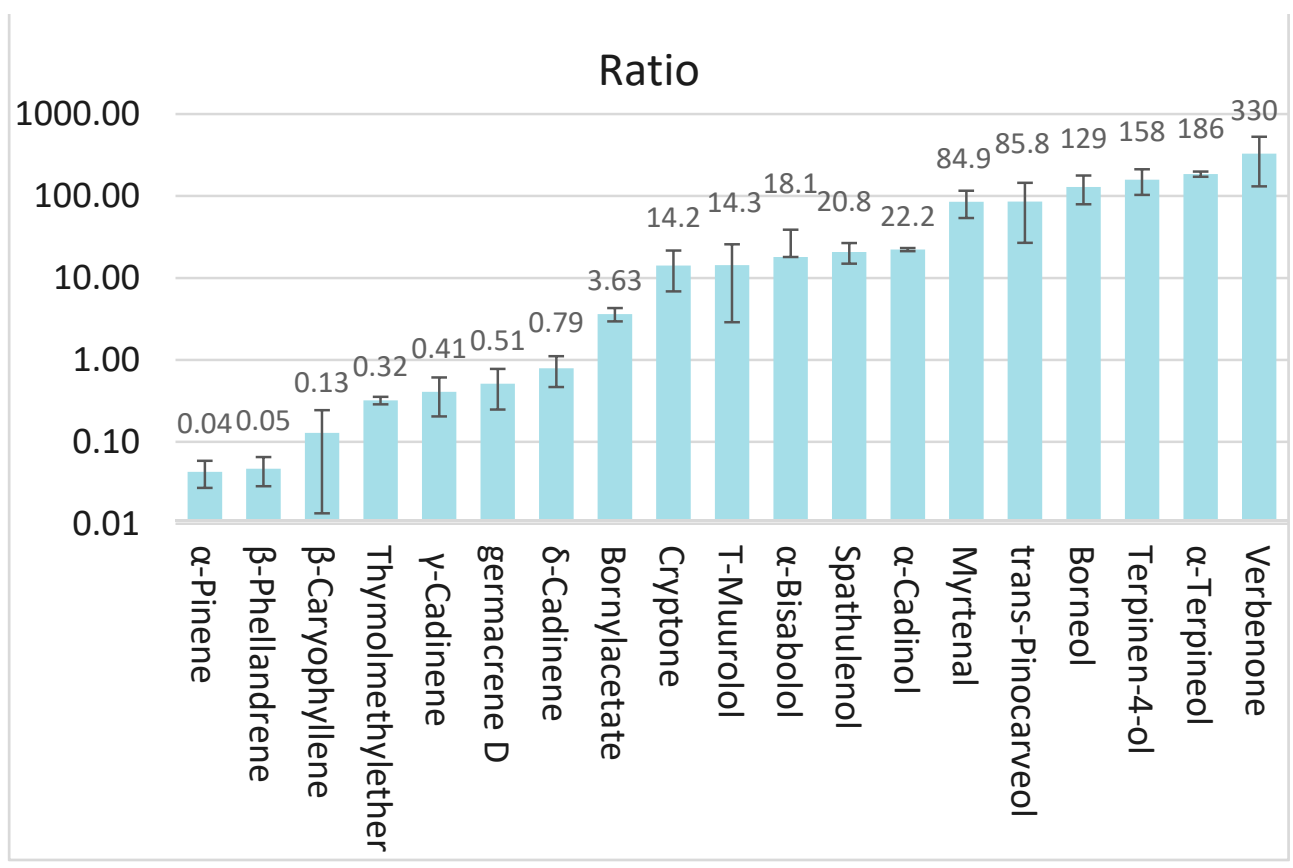

Figure 5. Ratio of volatile percentage in hydrolates to essential oils.

The fact that hydrolate volatiles are low in hydrocarbons and higher in oxygenized compounds has been reported for hydrolates from various plants. The essential oils from Abies alba and A. koreana cones and seeds is constituted by $82.4-93.4 \%$ monoterpene hydrocarbons, mainly $\alpha$-pinene and limonene, and in contrast the volatiles in the respective hydrolates were composed of $83.1-94.4 \%$ of oxidized monoterpenes [23]. While Picea glauca essential oil contained $20 \% \beta$-pinene and $12 \% \alpha$-pinene, these constituents were barely present in the hydrolates [24,25]. A Solidago puberula essential oil had $37.2 \% \alpha$-pinene and the respective hydrolate was devoid of it [25]. Similarly, myrcene and $\beta$-phellandrene, accounting together for $72-74 \%$ of the essential from Anthriscus sylvestris, occurred from traces to $1.6 \%$ in the hydrolate volatiles [26]. This distribution is, to a large extent, due to the low solubility of hydrocarbons in water; for monoterpene hydrocarbons such as $\alpha$-pinene, $\beta$-pinene, camphene, myrcene, and $\alpha$-phellandrene, the solubility is below $10 \mathrm{mg} / \mathrm{L}$ at $25^{\circ} \mathrm{C}$. The water solubility of $\alpha$-terpineol and erpinene-4-ol is reported to be 7100 and $387 \mathrm{mg} / \mathrm{L}$, respectively [27].

Additionally, the enrichment of oxidized compounds in the hydrolates is documented. The distilled oils from Myrica gale contained none to $0.2 \% \alpha$-terpineol, and none to $0.4 \%$ terpinen-4-ol, while the hydrolate volatiles accumulated these compounds to $11.3-15.6 \%$ and 13.4-14.3\%, respectively [28]. In the case of Teucrium kabylicum, a percentage of $0.4 \%$ terpinen- 4 -ol was found in the essential oil, and of $23.2 \%$ in the hydrolate volatile fraction [29].

The partition of a compound between the essential oil and the water phase of the hydrolate also depends on the solubility of the oil compound in the essential oil itself. $P$. cembra essential oil is composed of more than $90 \%$ terpene hydrocarbons, a very apolar matrix. This is a less favorable environment for oxygenated compounds, supporting their transfer into the water phase. Therefore, we obtained higher ratios (Figure 5) between hydrolate and essential oil for these compounds than those reported in the literature. For example, in the present study, camphor occurred up to $2.7 \%$ in the hydrolate volatiles, while in distilled oil it could only be found in traces $(<0.05 \%)$. In contrast, an enrichment of camphor at $65.5 \%$ occurred in the volatile fraction of a Picea glauca hydrosol where the corresponding essential oil had $20.2 \%$ of this compound [25].

A further factor influencing the composition of the hydrolate volatile fraction might be the distillation process itself, considering the dimensions of the distillation unit, the 
amount of water consumed, and the experimental duration. However, in this study, these factors could not be further investigated using a medium scale device operated under field conditions.

\section{Conclusions}

The hydrodistillation of Pinus cembra branches with needles gives an essential oil rich in monoterpene hydrocarbons, mainly $\alpha$-pinene and $\beta$-phellandrene. The hydrolates, as byproducts of the distillation process, had a different volatile fraction, where mainly oxygenated compounds were present, including even such compounds that are below the detection limit in the essential oil.

Author Contributions: Conceptualization, J.N. and R.C.; methodology, F.B. and S.S.; validation, J.N., F.B., and S.S.; formal analysis, F.B. and S.S.; Data curation, J.N.; writing-original draft preparation, R.C.; writing-review and editing, R.C. and J.N.; visualization, R.C., F.B.; supervision, J.N.; and project administration, J.N. All authors have read and agreed to the published version of the manuscript.

Funding: This research received no external funding.

Institutional Review Board Statement: Not applicable.

Informed Consent Statement: Not applicable.

Data Availability Statement: The data presented in this study are available on request from the corresponding author.

Acknowledgments: Open Access Funding by the University of Veterinary Medicine Vienna.

Conflicts of Interest: The authors declare no conflict of interest.

\section{References}

1. Schütt, P. Pinus Cembra. In Enzyklopädie der Holzgewächse; Roloff, A., Weissgerber, H., Lang, U.M., Stimm, B., Eds.; Wiley-VCH: Weinheim, Germany, 2014; p. 12.

2. Caudullo, G.; de Rigo, D. Pinus cembra in Europe: Distribution, habitat, usage and threats. In European Atlas of Forest Tree Species; San-Miguel-Ayanz, J., de Rigo, D., Caudullo, G., Houston Durrant, T., Mauri, A., Eds.; Publications Office of the European Union: Luxembourg, 2016; e01bd9b; pp. 120-121.

3. Wojnicka-Połtorak, A.; Celinski, K.; Chudzinska, E.; Prus-Głowacki, W.; Niemtur, S. Genetic resources of Pinus cembra L. marginal populations from the Tatra Mountains: Implications for conservation. Biochem. Genet. 2015, 53, 49-61. [CrossRef] [PubMed]

4. Boden, S.; Pyttel, P.; Eastaugh, C.S. Impacts of climate change on the establishment, distribution, growth and mortality of Swiss stone pine (Pinus cembra L.). iForest 2009, 3, 82-85. [CrossRef]

5. Weiss, G.; Ludvig, A.; Zivojinovic, I.; Asamer-Handler, M.; Huber, P. Non-timber innovations: How to innovate in side activities of forestry-Case study Styria, Austria. Austrian J. For. Sci. 2017, 134, 231-250.

6. Schmidt, E. Production of essential oils. In Handbook of Essential Oils; Baser, K.H.C., Buchbauer, G., Eds.; CRC-Press: Boca Raton, FL, USA, 2010; pp. 83-119.

7. Baldino, L.; Scognamiglio, M.; Reverchon, E. Supercritical fluid technologies applied to the extraction of compounds of industrial interest from Cannabis sativa L. and to their pharmaceutical formulations: A review. J. Supercrit. Fluids 2020, 165, 104960. [CrossRef]

8. Apetrei, C.L.; Spac, A.; Brebu, M.; Tuchilus, C.; Miron, A. Composition, and antioxidant and antimicrobial activities of the essential oils of a full-grown Pinus cembra L. tree from the Calimani Mountains (Romania). J. Serbian Chem. Soc. 2013, $78,27-37$. [CrossRef]

9. Kubeczka, K.H.; Schultze, W. Biology and chemistry of conifer oils. Flavour Fragr. J. 1987, 2, 137-148. [CrossRef]

10. Lis, A.; Kalinowska, A.; Krajewska, A.; Mellor, K. Chemical composition of the essential oils from different morphological parts of Pinus cembra L. Chem. Biodivers. 2017, 14, e1600345. [CrossRef] [PubMed]

11. Nikolić, B.; Todosijević, M.; Ratknić, M.; Đorđević, I.; Stanković, J.; Cvetković, M.; Marin, P.D.; Tešević, V. Terpenes and n-alkanes in needles of Pinus cembra. Nat. Prod. Commun. 2018, 13, 1035-1037. [CrossRef]

12. Dormont, L.; Roques, A.; Malosse, C. Cone and foliage volatiles emitted by Pinus cembra and some related conifer species. Phytochemistry 1998, 49, 1269-1277. [CrossRef]

13. Chizzola, R.; Müllner, K. Variability of volatiles in Pinus cembra L. within and between trees from a stand in the Salzburg Alps (Austria) as assessed by essential oil and SPME analysis. Genet. Resour. Crop Evol. 2021, 68, 567-579. [CrossRef]

14. Silori, G.K.; Kushwaha, N.; Kumar, V. Essential oils from pines: Chemistry and applications. In Essential Oil Research; Malik, S., Ed.; Springer Nature: Cham, Switzerland, 2019; pp. 275-297. [CrossRef] 
15. Adams, R.P. Identification of Essential Oil Components by Gas Chromatography/Quadrupole Mass Spectroscopy, 4th ed.; Allured: Carol Stream, IL, USA, 2007.

16. McLafferty, F.W. Registry of Mass Spectral Data, 5th ed.; Wiley: New York, NY, USA, 1989.

17. Hänsel, R.; Sticher, O. Pharmakognosie-Phytopharmazie, 9th ed.; Springer Medizinverlag: Heidelberg, Germany, $2010 ;$ p. 1014.

18. Basholli-Salihu, M.; Schuster, R.; Hajdari, A.; Mulla, D.; Viernstein, H.; Mustafa, B.; Mueller, M. Phytochemical composition, anti-inflammatory activity and cytotoxic effects of essential oils from three Pinus spp. Pharm. Biol. 2017, 55, 1553-1560. [CrossRef] [PubMed]

19. Ioannou, E.; Koutsaviti, A.; Tzakou, O.; Roussis, V. The genus Pinus. A comparative study on the needle essential oil composition of 46 pine species. Phytochem. Rev. 2014, 13, 741-768. [CrossRef]

20. Kännaste, A.; Copolovici, L.; Pazouki, L.; Suhhorutsenko, M.; Niinemets, Ü. Highly variable chemical signatures over short spatial distances among Scots pine (Pinus sylvestris) populations. Tree Physiol. 2013, 33, 374-387. [CrossRef] [PubMed]

21. Keefover-Ring, K.; Linhart, Y.B. Variable chemistry and herbivory of Ponderosa pine cones. Int. J. Plant Sci. 2010, 171, $293-302$. [CrossRef]

22. Jäger, W. Metabolism of terpenoids in animal models and humans. In Handbook of Essential Oils; Baser, K.H.C., Buchbauer, G., Eds.; CRC-Press: Boca Raton, FL, USA, 2010; pp. 209-234.

23. Wajs-Bonikowska, A.; Sienkiewicz, M.; Stobiecka, A.; Maciag, A.; Szoka, L.; Karna, E. Chemical composition and biological activity of Abies alba and A. koreana seed and cone essential oils and characterization of their hydrolates. Chem. Biodivers. 2015, 12, 407-418. [CrossRef] [PubMed]

24. Garneau, F.X.; Collin, G.; Gagnon, H.; Pichette, A. Chemical composition of the yydrosol and the essential oil of three different species of the Pinaceae family: Picea glauca (Moench) Voss., Picea mariana (Mill.)B.S.P., and Abies balsamea (L.) Mill. J. Essent. Oil Bear. Plants 2012, 15, 227-236. [CrossRef]

25. Garneau, F.-X.; Collin, G.; Gagnon, H. Chemical composition and stability of the hydrosols obtained during essential oil production. II. The case of Picea glauca (Moench) Voss., Solidago puberula Nutt., and Mentha piperita L. Am. J. Essent. Oils Nat. Prod. 2014, 2, 29-35.

26. St-Gelais, A.; Caron, L.; Collin, G.; Marceau, H.; Pichette, A. Aromas from Quebec. III. Composition of the essential oil and hydrolate of the roots of Anthriscus sylvestris (L.) Hoffm. from Saguenay. J. Essent. Oil Res. 2015, 27, 373-379. [CrossRef]

27. National Institutes of Health (HIH). PubChem Open Chemistry Database. Available online: https://pubchem.ncbi.nlm.nih.gov/ compound/ (accessed on 27 May 2021).

28. Wawrzynczak, K.; Sadowska, B.; Więckowska-Szakiel, M.; Kalemba, D. Composition and antimicrobial activity of Myrica gale L. leaf and flower essential oils and hydrolates. Rec. Nat. Prod. 2020, 15, 35-45. [CrossRef]

29. Selles, C.; Lemouchi, R.; Dib, M.E.A. Chemical constituents of essential oil and hydrosol extract from Teucrium kabylicum Batt., an endemic species from Algeria. Agric. Conspec. Sci. 2020, 85, 375-377. 